REFERENCE Dewart, G. 1966. Moulins on Kaskawulsh Glacier, Yukon Territory. Fournal of Glaciology, Vol. 6, No. 44, p. 320-21 .
[Letter.]

SIR,

The regime of the western part of the Ross Ice Shelf drainage system

I am writing to you in connection with the article by Giovinetto and others (1966). In this paper the results of studies on the glaciers flowing through the Trans-Antarctic Mountains are very interesting.

Unfortunately there are two comments which must be made concerning the study of the regime of the drainage basin of these glaciers:

(a) The delineation of the drainage basin is purely hypothetical.

(b) The supposition that all the ice in this hypothetical basin flows exclusively through the glaciers mentioned, and that no ice crosses the western, southern or northern boundaries of this hypothetical drainage basin, cannot be justified at all.

It follows from this that a calculation of errors applied to the terms in the mass balance is nothing but an illusion, as it is not the error calculation which gives precision to a calculation, but the reality of the quantities one uses.

The positive budget they report is therefore of no significance.

Centre d'Études Glaciologiques des Régions Arctiques et Antarctiques,

Face au 22, Quai Carnot, 92 Saint-Cloud, France

23 March 1967

A. BAuER

\title{
REFERENCE
}

Giovinetto, M. B., and others. 1966. The regime of the western part of the Ross Ice Shelf drainage system, by M.[B.]Giovinetto, E. S. Robinson and C. W. M. Swithinbank. Journal of Glaciology, Vol. 6, No. 43, p. 55-68.

SIR,

\section{Accumulation between Mount Chapman and "Byrd" station, Antarctica}

I had the opportunity to re-measure the snow accumulation along the line of the "Byrd" stationMount Chapman ice-movement markers (Brecher, 1967) this past Antarctic season. It seems to me rather interesting to note that while the mean accumulation between "Byrd" station and array V (300 km. from "Byrd" station) has decreased markedly, from $\mathrm{I} 6 \cdot \mathrm{I}$ g. $\mathrm{cm} .^{-2} \mathrm{yr}^{-1}$ for $1962-65$ to $\mathrm{II} \cdot 5$ g. cm. ${ }^{-2} \mathrm{yr}^{-1}$ in $1965-66$ (the value between arrays V and VI has remained unchanged), the variations of accumulation along the line correspond very closely for the two time intervals with a coefficient of correlation of $0 \cdot 926$. This could well be a topographic effect.

The decrease of accumulation with time has also been observed at "Byrd" station, where measurements of Ioo stakes have shown a decrease from $\mathrm{II} \cdot 0 \mathrm{~g} . \mathrm{cm} .^{-2} \mathrm{yr} .^{-1}$ to $9 \cdot 4 \mathrm{~g} . \mathrm{cm}^{-2} \mathrm{yr}^{-1}$ for this same time period (personal communication from R. L. Cameron).

My paper (Brecher, 1967) contained some minor errors which should be corrected as follows:

i. On p. 575 , lines 8 and 9 , the standard deviations should be $3 \cdot 0$ and $3 \cdot 1$, respectively.

ii. On p. 575, Table I, the column heading "Standard deviation" should read "Standard error". The values were obtained from the following expressions:

$$
\text { Standard error of mean }=\left\{\frac{\sum v^{2}}{n(n-1)}\right\}^{1}
$$

Standard error of one observation $=\left(\Sigma v^{2} / n\right)^{\frac{1}{2}}$,

where $\Sigma v^{2}$ is the sum of the squares of the deviations from the mean and $n$ is the number of observations, and the observations are considered to be several measurements of the same quantity.

Institute of Polar Studies,

Ohio State University,

H. H. BRECHER

125 South Oval Drive,

Columbus, Ohio 432Io, U.S.A.

7 May 1967 